\title{
Edema reducing potentials of some emerging Schiff's bases of murrayanine
}

\begin{abstract}
Inflammation is the most common problem among the human population where age-related or physical challenges contribute to pain, edema, and discomfort. Schiff base containing molecules are in general referred to a group of compounds having an azomethine $(\mathrm{C}=\mathrm{N})$ component which is formed chemically by the condensation reaction of the primary amines $\left(-\mathrm{NH}_{2}\right)$ and active carbonyl group $(\mathrm{C}=\mathrm{O})$ have potential anti-inflammatory activity. In the current research, Schiff's base derivatives ( 3 and 5) of murrayanine were rationally fabricated and the anti-inflammatory potential was explored by utilizing carrageenan-induced paw edema method. The compound (3) expressed the highest activity utilizing carrageenan-induced paw edema method with $\%$ edema reduction of $29.74,41.33$, and 56.28 , respectively at $1 \mathrm{hr}, 2 \mathrm{hrs}$, and $3 \mathrm{hrs}$. However, the anti-inflammatory potential of compound (5) was nearly the same with \% edema reduction of $17.91,35.86$, and 48.67 , respectively at 3 different time intervals. But, both the compounds can be regarded as the potential candidates, since the compounds have a very less difference in biological activity. Clear structureactivity-relationships (SAR) cannot be predicted from the study. The current research will definitely provide clues to the medicinal chemists in developing better antiinflammatory agents in the upcoming future and will open new perspectives of research in this direction.
\end{abstract}

Keywords: anti-inflammatory, characterization, edema, murrayanine, Schiff base, synthesis
Volume 2 Issue 4 - 2018

\author{
Debarshi Kar Mahapatra,' Kanhaiya M \\ Dadure, ${ }^{2}$ Ruchi S Shivhare ${ }^{3}$ \\ 'Department of Pharmaceutical Chemistry, Dadasaheb Balpande \\ College of Pharmacy, India \\ ${ }^{2}$ Department of Chemistry, JB College of Science, India \\ ${ }^{3}$ Department of Pharmaceutical Chemistry, Kamla Nehru \\ College of Pharmacy, India
}

\author{
Correspondence: Debarshi Kar Mahapatra, PhD Assistant \\ Professor, Department of Pharmaceutical Chemistry, \\ Dadasaheb Balpande College of Pharmacy, Nagpur 440037, \\ Maharashtra, India, Tel +91835782 I88I, \\ Email mahapatradebarshi@gmail.com,dkmbsp@gmail.com
}

Received: July 0I, 2018 | Published: July II, 2018

\section{Introduction}

Murrayanine is the most active and popular phytoconstituent present in the Indian curry plant, also known as Murraya koenigii $L$. (family: Rutaceae). ${ }^{1}$ Till date, the ethnopharmacological importance of the root, stem bark, and leaves are known successfully such as purgative, anthelminthic, febrifuge, carminative, astringent, and stomachic. ${ }^{2}$ In our previous research done so far, benzothiazepine, ${ }^{3}$ oxadiazole, ${ }^{4} \quad 3,4$-methylenedioxy, ${ }^{5}$ thiazole, ${ }^{6}$ benzoxazepine, ${ }^{7}$ thiadiazole,${ }^{8}$ isoxazole, ${ }^{9}$ hydantoin, ${ }^{10}$ phthalimide, ${ }^{11}$ pyrimidine, ${ }^{12}$ benzodiazepine, ${ }^{13}$ pyrazole, ${ }^{14}$ chalcone, ${ }^{15}$ and methylsulfone ${ }^{16}$ derivatives of murryanine have been rationally synthesized as hybrids in our laboratory, characterized comprehensively, and biologically screened in various animal models to explore their pharmacological potentials such as anti-convulsant, anti-inflammatory, anti-anxiety, anti-diabetic, anti-oxidant, anti-fungal, and anti-bacterial.

Inflammation is the most common problem among the human population where age-related or physical challenges contribute to pain, edema, and discomfort. ${ }^{17}$ The area of drug discovery is never ending since each of the drugs has some or the other disadvantages such as GIT side-effects. ${ }^{18}$ Schiff base containing molecules are in general referred to the group of compounds having an azomethine $(\mathrm{C}=\mathrm{N})$ component which is formed chemically by the condensation reaction of the primary amines $\left(-\mathrm{NH}_{2}\right)$ and active carbonyl group $(\mathrm{C}=\mathrm{O}) .{ }^{19}$ The molecules with Schiff's bases component have been known to exhibit potential anti-cancer, anti-inflammatory, anti-bacterial, anti-fungal, anthelmintic, anti-depressant, anti-convulsant, etc. ${ }^{20}$ In this line of experiment, our research group had already explored the heterocyclic moieties such as thiazole, oxadiazole, and thiadiazole from the Schiff's base of murrayanine where anti-inflammatory potentials have been determined. In the current research, Schiff's base derivatives ( 3 and 5) of murrayanine were rationally fabricated and the anti-inflammatory potential was explored by utilizing carrageenan-induced paw edema method.

\section{Materials and methods}

\section{Chemicals and instrumentation}

The chemical synthesis involved murrayanine, the starting material which was obtained from the powdered M. koenigii stem bark by employing the soxhlation method as per the protocol described previously in the report. The chemical reactants and solvents were of analytical grade and obtained a local chemical vendor of Sigma Aldrich, Germany franchisee. The progress of the chemical reactions was monitored by using Merck ${ }^{\circledR}$ silica gel-G pre-coated TLC plates. The chemical structures were elucidated through sophisticated techniques. Fourier Transformed Infrared (FTIR) Spectroscopy (Shimadzu ${ }^{\circledR}$ IRAffinity-1 instrument; expressed in $\mathrm{cm}^{-1}$ ), tetramethylsilane assisted calibrated ${ }^{1} \mathrm{H}$ (proton)-NMR (Bruker Avance-II instrument; expressed in ppm), Mass Spectroscopy (MICROMASS Q-TOF instrument), and CHN analyses (PerkinElmer Elemental Analyzer 2400 instrument).

\section{Animals}

Based on our previous anti-inflammatory protocol, albino rats of age 5 to 6 weeks age, 150-230g body weight was utilized. After obtaining permission from the Department Ethical Committee and with compliance with the CPCSEA (1389/a/10/CPCSEA), the 
experiment was performed on the rats kept in the animal house under the conditions of $25-26^{\circ} \mathrm{C}$ temperature, humidity $50-65 \%, 12 \mathrm{hr}$ light and dark. The rats were kept in polypropylene cage (two animals per cage), standard rodent pellets were fed, and given free access to water.

\section{Synthesis of target compounds}

The two new molecules were fabricated from the murrayanine (1), an active carbazole derivative. To develop the Schiff's base compounds, the active aldehydes portion of the murrayanine (1) was utilized and made to react with the carbonyl function which results in the formation of azomethine components ( 3 and 5). The mechanism entailed an electrophilic attack of the aldehyde carbon (of murrayanine) with the nucleophilic amine of the reactant (2 and 4). The final compounds and their synthesis pathway are mentioned in Figure 1.

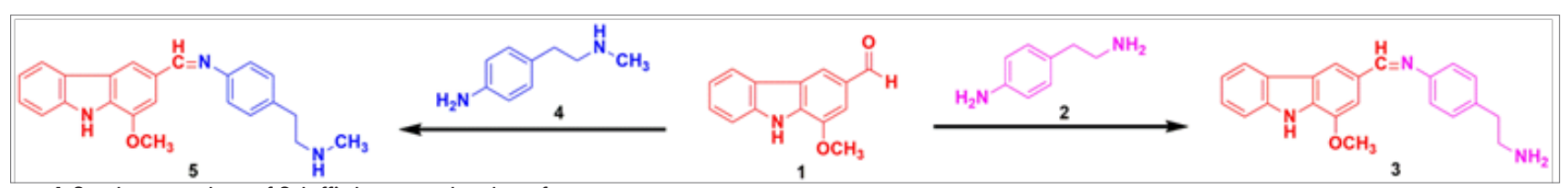

Figure I Synthesis outline of Schiff's bases molecules of murrayanine.

\section{Synthetic protocol for (Z)-4-(2- (amino)/ (methylamino)-ethyl)-N-((I-methoxy-9H-carbazol-3- yl)methylene)aniline}

Equal molar concentrations of murrayanine (1) and 4-(2-aminoethyl)aniline (2) or 4-(2-(methylamino)ethyl)aniline (4) were made to react in a round bottom flask in the presence of ethanol to form the solution. Both the reaction mixtures were made to reflux for the duration of $6 \mathrm{hr}$ in the presence of 7 to 8 drops of glacial acetic acid. The reaction contents were subsequently cooled to obtain the product. The procured compounds were thoroughly washed with icecold water, properly dried, and recrystallized with an aqueous ethanol solution.

\section{(Z)-4-(2-aminoethyl)-N-(( I-methoxy-9H-carbazol-3-yl) methylene)aniline (3)}

$44 \%$ yield; FTIR $(\mathrm{KBr}) \cup\left(\mathrm{cm}^{-1}\right): 3287\left(-\mathrm{NH}_{2}\right.$, stretching), 3146 (-NH, stretching), 3021 (C-H, aromatic), $1689(\mathrm{C}=\mathrm{N}$, azomethine), $1624\left(\mathrm{C}=\mathrm{C}\right.$, aromatic), 1555(-NH, bending), $1472\left(-\mathrm{CH}_{2}\right.$, bending), 1261(C-N, stretching), 1203(C-O); ${ }^{1} \mathrm{H}$ NMR ( $\delta$, ppm, $\left.\mathrm{CDCl}_{3}\right): 10.24$ $(9,1 \mathrm{H}), 8.25(10,1 \mathrm{H}$, azomethine), 7.3-8.3 (Aromatic, $10 \mathrm{H}), 5.07$ (18, 2H), 3.95 (1, 3H), $3.08(17,2 \mathrm{H}), 2.91$ (16, 2H). MS: M+343. Anal. Calcd. for $\mathrm{C}_{23} \mathrm{H}_{21} \mathrm{~N}_{3} \mathrm{O}$ : C, 76.94; $\mathrm{H}, 6.16 ; \mathrm{N}, 12.24$. Found: C, 76.15; H, 5.66; N, 11.78

\section{(Z)-N-(( I-methoxy-9H-carbazol-3-yl)methylene)-4-(2- (methylamino)ethyl)aniline (5)}

59\% yield; FTIR (KBr) v ( $\left.\mathrm{cm}^{-1}\right): 3159$ (-NH, stretching), 3077 (C-H, aromatic), $1701(\mathrm{C}=\mathrm{N}$, azomethine), $1618(\mathrm{C}=\mathrm{C}$, aromatic), 1637(-NH, bending), 1482 (- $\mathrm{CH}_{2}$, bending), 1296 (C-N, stretching), 1244 (C-O); ${ }^{1} \mathrm{H}$ NMR ( $\delta$, ppm, $\left.\mathrm{CDCl}_{3}\right): 10.17(9,1 \mathrm{H}), 8.34(10,1 \mathrm{H}$, azomethine), 7.1-8.6 (Aromatic, 10H), $3.86(1,3 \mathrm{H}), 3.37(19,3 \mathrm{H})$, $3.11(17,2 \mathrm{H}), 2.83(16,2 \mathrm{H})$. MS: $\mathrm{M}^{+} 357$. Anal. Calcd. for $\mathrm{C}_{22} \mathrm{H}_{23} \mathrm{NO}_{3}$ : C, 77.28; H, 6.49; N, 11.76. Found: C, 76.94; H, 6.16; N, 11.23

\section{Acute toxicity studies}

Accordance to the OECD protocol, the in vivo safety limit of the molecules was estimated in the increasing dose in the range $25 \mathrm{mg} / \mathrm{kg}$ to $500 \mathrm{mg} / \mathrm{kg}$. The safe dose of the molecules was computed based on the $\mathrm{LD}_{50}$ values to determine the point at which maximum therapeutic effect can be achieved without any possible toxic symptoms. ${ }^{21}$

\section{Anti-inflammatory screening}

The carrageenan-induced paw edema method was utilized for the determination of in vivo anti-inflammatory activity. The protocol involved the following segments, where at first, the rats were fasted throughout the night to minimize the disparities duration of the edema data collection. Secondly, before initiating the exploration of the edema reducing potential of the molecules, $5 \mathrm{~mL}$ distilled water was administered through the oral route to the experimental animals. The control group of the rats received $0.9 \%$ saline solution containing a few drops of solubilizer Tween 80 . The experimental groups were given $1 \%$ carrageenan solution via injection route at the subplanter region of the right hind paw. At penultimate stage, the rats orally received $100 \mathrm{mg} / \mathrm{kg}$ b.w. of the compounds (suspended in $0.9 \%$ saline solution) an hour before the commencement of the study. Finally, the thickness of the rat paw was determined by using mercury digital micrometer for the duration of $3 \mathrm{hrs}$ with $1 \mathrm{hr}$ interval. The edema reduction potential was estimated by computing the differences between the width of the injected paws and the non-injected paws. ${ }^{22}$

\section{Statistical treatment}

The obtained anti-inflammatory data were statistically analyzed by ANOVA method (one-way) followed by the Dunnett's multiple comparisons test. The P-value of less than 0.01 was regarded as statistically significant.

\section{Results and discussion}

\section{Chemistry}

The structural elucidation of the murrayanine based Schiff's base compounds by utilizing the spectroscopic characterization revealed that the compounds were formed completely. The compound (3) demonstrated the appearance of the Schiff's base (noticed at $1689 \mathrm{~cm}$ 1 in FT-IR spectra; and $8.25 \mathrm{ppm}$ ) which confirmed the formation of the proposed template. The disappearance of the carbonyl group $\left(1729 \mathrm{~cm}^{-1}\right)$ at the spectra of murrayanine, additionally confirmed the formation of the desired molecule. The FT-IR spectra of murrayanine part represented the presence of $\mathrm{C}=\mathrm{C}$ stretching, $\mathrm{C}-\mathrm{H}$ stretching, $\mathrm{N}-\mathrm{H}$ stretching, N-H bending, C-N stretching, and C-O stretching at $1624 \mathrm{~cm}^{-1}, 3146 \mathrm{~cm}^{-1}, 1555 \mathrm{~cm}^{-1}, 1261 \mathrm{~cm}^{-1}$ and $1203 \mathrm{~cm}^{-1}$, respectively. Similarly, the ${ }^{1} \mathrm{H}-\mathrm{NMR}$ spectra presented the appearance of peaks of $-\mathrm{NH}$ and $-\mathrm{OCH}_{3}$ at $10.24 \mathrm{ppm}$ and $3.95 \mathrm{ppm}$, respectively. The amine-containing portion was characterized by the presence of $-\mathrm{NH}_{2}$ stretching at $3146 \mathrm{~cm}^{-1}$ and $-\mathrm{CH}_{2}$ stretching at $1472 \mathrm{~cm}^{-1}$ at FT-IR spectra. Quite similarly, the ${ }^{1} \mathrm{H}-\mathrm{NMR}$ spectra expressed peaks of $\mathrm{NH}_{2}$ and the two alkane portions at $5.07 \mathrm{ppm}, 3.08 \mathrm{ppm}$ and $2.91 \mathrm{ppm}$, respectively.

The compound (5) presented the emergence of the Schiff's base (noticed at $1701 \mathrm{~cm}^{-1}$ in FT-IR spectra; and $8.34 \mathrm{ppm}$ ) 
which substantiates the fabrication of the proposed template. The disappearance of the carbonyl group $\left(1729 \mathrm{~cm}^{-1}\right)$ at the spectra of murrayanine, additionally confirmed the development of required molecule. The FT-IR spectra of murrayanine part signified the existence of $\mathrm{C}=\mathrm{C}$ stretching, $\mathrm{C}-\mathrm{H}$ stretching, $\mathrm{N}-\mathrm{H}$ stretching, $\mathrm{N}-\mathrm{H}$ bending, C-N stretching, and C-O stretching at $1618 \mathrm{~cm}^{-1}, 3159 \mathrm{~cm}^{-}$ ${ }^{1}, 1637 \mathrm{~cm}^{-1}, 1296 \mathrm{~cm}^{-1}$, and $1244 \mathrm{~cm}^{-1}$, respectively. Similarly, the ${ }^{1} \mathrm{H}-\mathrm{NMR}$ spectra presented the appearance of peaks of $-\mathrm{NH}$ and $\mathrm{OCH}_{3}$ at $10.17 \mathrm{ppm}$ and $3.86 \mathrm{ppm}$, respectively. The methylamine containing portion was exemplified by the presence of $-\mathrm{CH}_{2}$ stretching at $1482 \mathrm{~cm}^{-1}$ at FT-IR spectra. Quite similarly, the ${ }^{1} \mathrm{H}-\mathrm{NMR}$ spectra exhibited peaks of methyl group protons and two alkane portions at $3.37 \mathrm{ppm}, 3.11 \mathrm{ppm}$ and $2.83 \mathrm{ppm}$, respectively. A marked variation between both the molecules was the disappearance of amine $\left(-\mathrm{NH}_{2}\right)$ peak in the proton-NMR spectra of compounds (5).

The mass spectra revealed the existence of base peaks corresponding exactly with that of the theoretical molecular mass of both the compounds. In addition to it, several fragment peaks $(\mathrm{m} / \mathrm{z}$ range: 100-200) appeared as well in the mass spectra. The CHN analyses further supported the fabricated as suggested from the observed $\%$ values.

\section{Acute toxicity study}

Both the derivatives (3) and (5) demonstrated no such toxic effects over the accelerated tested dose range of $25 \mathrm{mg} / \mathrm{kg}$ to $500 \mathrm{mg} / \mathrm{kg}$. The in vivo anti-inflammatory potential of the molecules were tested at $150 \mathrm{mg} / \mathrm{kg}$ b.w.

\section{Anti-inflammatory activity}

The compound (3) expressed the highest in vivo anti-inflammatory activity utilizing carrageenan-induced paw edema method with \% edema reduction of $29.74,41.33$, and 56.28 , respectively at $1 \mathrm{hr}, 2 \mathrm{hrs}$, and $3 \mathrm{hrs}$. However, the anti-inflammatory potential of compound (5) was nearly the same with \% edema reduction of $17.91,35.86$, and 48.67 , respectively at 3 different time intervals. The compound (3) expressed better activity than that of the molecule (5) since it consists of an additional $-\mathrm{NH}_{2}$ group which may provide supplementary hydrogen bond formation with the inflammatory targets like cyclooxygenase-1/2 (COX-1/2) and lipoxygenase (LOX). However, no structure-activity-relationships (SARs) cannot be predicted from this study. A comparable or somewhat better anti-inflammatory has been perceived for the fabricated molecules (3) and (5) when compared with the previously synthesized murrayanine hybrid derivatives (Table 1).

Table I Exploring in vivo anti-inflammatory activity of the murrayanine Schiff's base erivatives

\begin{tabular}{llll}
\hline \multirow{2}{*}{ Group } & \multicolumn{3}{l}{ Percentage (\%) inhibition of edema } \\
\cline { 2 - 4 } & $\mathrm{Ihr}$ & $\mathbf{2 h r}$ & $3 \mathrm{hr}$ \\
\hline 5 & $17.91 \pm 1.66$ & $35.86 \pm 1.43$ & $48.67 \pm 1.39$ \\
3 & $29.74 \pm 1.57$ & $41.33 \pm 1.16$ & $56.28 \pm 1.23$ \\
Indomethacin & $46.56 \pm 1.18$ & $59.81 \pm 1.33$ & $73.94 \pm 1.74$ \\
\hline
\end{tabular}

$\mathrm{n}=6 ; \mathrm{ED}_{50}$ of $150 \mathrm{mg} / \mathrm{kg}$ b.w. in male adult albino mice; $\mathrm{P}<0.01$.

\section{Conclusion}

The present investigation emphasized on the importance of two prominent Schiff's base molecules (3) and (5) as anti-inflammatory agents. Murrayanine, itself is having a very low anti-inflammatory potential, finds application in edema reduction as a semi-synthetic Schiff's base component. On comparison with the previously synthesized murrayaine-heterocyclic hybrids (pyrimidine, ${ }^{12}$ oxadiazole, ${ }^{4}$ thiadiazole, ${ }^{8}$ and 3,4 -methylenedioxy ${ }^{5}$ ), it has been observed that the Schiff's base analogs displayed noteworthy activity. Moreover, a comparable anti-inflammatory activity has been observed than the standard drug (indomethacin). However, a clear SAR cannot be predicted from this study but the edema reducing potentials of both the Schiff's bases were found to be better than the parent compound (murrayanine). The current research will definitely provide clues to the (medicinal)-chemists across the globe in rationally developing better Schiff's bases based anti-inflammatory agents having pronounced activity than that of the parent molecules in the upcoming future and will also open new opportunities for research in utilizing semisynthetic approaches.

\section{Acknowledgements}

Authors are highly thankful to Savitribai Phule Pune University, Pune, Maharashtra, India for providing research grants (Grant No. 13PHM000126).

\section{Conflict of interest}

Author declares that there is no conflict of interest.

\section{References}

1. Shivhare RS, Mahapatra DK, Nair RR, et al. Schiff's base derivatives of murrayanine demonstrated enhanced anti-oxidant activity than its parent moiety. Indian J Pharm Edu Res. 2016;50(4):9-15.

2. Iyer D, Devi U. Phyto-pharmacology of Murraya koenigii (L.). Pharmacognosy Reviews. 2008;2(3):180-184.

3. Mahapatra DK, Shivhare RS, Asati V. Locomotor inhibitory activity of some Murrayanine-Chalcone based 2,3-dihydrobenzo[b][1,4]thiazepine derivatives: Exploring Anxiolytic potentials. Chron Pharm Sci. 2018;2(1):462-468.

4. Mahapatra DK, Shivhare RS, Ugale VG. Anti-inflammatory potentials of some novel Murrayanine containing 1,3,4-Oxadiazole derivatives. Asian J Pharm Tech. 2018;8(1):47-51.

5. Mahapatra DK, Shivhare RS. 3',4'-Methylenedioxy Moiety Containing Murrayanine Based Chalcone as Emerging Anti-inflammatory Agent. $J$ Mod Chem Chem Technol. 2018;9(1):12-16.

6. Mahapatra DK, Shivhare RS, Joseph TM. Design and characterization of Murrayanine linked Isoxazole derivatives: Novel class of bacteriocidal agents. Int J Res Drug Pharm Sci. 2017;1(1):11-15.

7. Mahapatra DK, Shivhare RS, Gupta SD. Anxiolytic activity of some 2,3-dihydrobenzo[b][1,4]oxazepine derivatives synthesized from Murrayanine-Chalcone. Asian J Res Pharm Sci. 2018;8(1):25-29.

8. Mahapatra DK, Shivhare RS, Haldar AGM. Novel Schiff's base containing Murrayanine-1,3,4-Thiadiazole Hybrids as potential anti-inflammatory agents. Asian J Chem Pharm Sci. 2017;2(2):10-15.

9. Mahapatra DK, Das D, Shivhare RS. Substituted thiazole linked murrayanine-Schiff's base derivatives as potential anti-breast cancer candidates: Future EGFR Kinase inhibitors. Int J Pharm Sci Drug Res. 2017;9(3):139-144.

10. Mahapatra DK, Das D, Shivhare RS, et al. Murrayanine-hydantoin and -thiohydantoin analogs as promising anti-convulsant agents: Synthesis, Characterization and Molecular Docking Studies. MOJ Bioorg Org Chem. 2018;2(2):47-51.

11. Mahapatra DK, Shivhare RS. Synthesizing an anti-oxidant principle 2-(((1-methoxy-9H-carbazol-3-yl)methylene)amino)isoindoline-1,3dione from $\mathrm{N}$-aminophthalimide and murrayanine. Inventi Med Chem. 2017;2017(4):1-3. 
12. Mahapatra DK, Shivhare RS, Kumar P. Murrayanine-chalcone transformed into novel pyrimidine compounds demonstrated promising anti-inflammatory activity. Asian J Pharm Res. 2018;8(1):6-10.

13. Mahapatra DK, Shivhare RS, Dadure KM. Transforming MurrayanineChalcone into corresponding $3 \mathrm{H}-\mathrm{benzo}[\mathrm{b}][1,4]$ diazepine derivatives: Accessing the anti-anxiety effect by inhibition of locomotor activity. Acta Sci Pharm Sci. 2018;2(5):40-44.

14. Mahapatra DK, Shivhare RS, Bharti SK. Novel Murrayanine based Pyrazole analogs as emerging anti-fungal candidates: Design, synthesis, characterization, and in vitro evaluation. Res Pharmaceut. 2017;1(1):1-5.

15. Mahapatra DK, Chhajed SS, Shivhare RS. Development of MurrayanineChalcone hybrids: An effort to combine two privilege scaffolds for enhancing hypoglycemic activity. Int $J$ Pharm Chem Anal. 2017;4(2):30-34.

16. Mahapatra DK, Shivhare RS. Anti-microbial Perspective of a Chalcone, (E)-1-(1-methoxy-9H-carbazol-3-yl)-3-(4-(methylsulfonyl) phenyl)prop2-en-1-one: Fabrication of a Hybrid by Unification of a Natural Product with a Synthetic Component. Int J Agr Life Sci. 2018;4(2):236-240.

17. Asati V, Bajaj S, Mahapatra DK, et al. Molecular modeling studies of some thiazolidine-2, 4-dione derivatives as 15-PGDH inhibitors. Med
Chem Res. 2016;25(1):94-108.

18. Mahapatra DK, Bharti SK. Handbook of Research on Medicinal Chemistry. New Jersey: Apple Academic Press, 2017.

19. Chhajed SS, Chaskar S, Kshirsagar SK, et al. Rational design and synthesis of some PPAR- $\gamma$ agonists: Substituted benzylideneamino-benzylidenethiazolidine-2, 4-diones. Comp Biol Chem. 2017;67:260-265.

20. Abu-Dief AM, Mohamed IM. A review on versatile applications of transition metal complexes incorporating Schiff bases. Beni-suef Univ J Basic Appl Sci. 2015;4(2):119-133.

21. Kanhed AA, Mehere AP, Pandey KR, et al. 4-(2-chloroacetamido) Benzoic Acid Derivatives as Local Anesthetic Agents: Design, Synthesis, and Characterization. UK J Pharm Biosci. 2016;4(6):35-44.

22. Amdare MD, Jogdand KR, Kathane LL, et al. Synthesis of a potential anti-inflammatory pyrazole derivative from hippuric acid as the starting material. J Pharm Chem Biol Sci. 2017;5(3):216-220. 